\title{
Aggressive angiomyxoma of vagina mimicking genital prolapse: a case report and review of literature
}

\author{
Mona Dahiya $^{1 *}$, Chandra Singhal ${ }^{1}$, Satish Bansal ${ }^{2}$, Umesh Jindal ${ }^{3}$
}

\author{
${ }^{1}$ Department of Obstetrics and Gynaecology, ${ }^{2}$ Department of Surgery, ${ }^{3}$ Department of Pathology, Maharaja Agrasen \\ Medical College, Agroha, Hissar, India
}

Received: 05 June 2015

Accepted: 09 July 2015

\author{
*Correspondence: \\ Dr. Mona Dahiya, \\ E-mail: monadahiya1@gmail.com
}

Copyright: $(\odot$ the author(s), publisher and licensee Medip Academy. This is an open-access article distributed under the terms of the Creative Commons Attribution Non-Commercial License, which permits unrestricted non-commercial use, distribution, and reproduction in any medium, provided the original work is properly cited.

\begin{abstract}
Aggressive angimyxoma is a rare locally infiltrative mesenchymal neoplasm which arises in the pelvic and perineal regions of young women. It has a high rate of local recurrence because of infiltrative growth and anatomical location making complete excision with wide margins difficult. We present a rare case of a young woman who came with history of something coming out per vaginum. Clinical examination and imaging studies revealed an elongated mass arising from the anterior vaginal wall protruding outside the introitus .A diagnostic biopsy revealed provisional diagnosis of spindle cell tumour. Enucleation of the mass was done and the histopathology report confirmed the diagnosis of aggressive angimyxoma. It was concluded that, Aggressive angiomyxoma is a rare benign, site specific, hormone dependant mesenchymal tumour occurring in young females. It is a masquerader and should be distinguished from other benign conditions. The case is presented for its rarity and stressing the need for a high index of suspicion in diagnosing differentials of vaginal and vulval mass. Long term follows up and careful monitoring is necessary to rule out the possibility of recurrence.
\end{abstract}

Keywords: Angiomyxoma, Vagina, Neoplasm

\section{INTRODUCTION}

Aggressive angiomyxoma is a rare deep soft tissue tumour mostly occurring in the pelviperineal regions of young female patients. As the name suggests, it may have a locally aggressive course and may exert pressure on adjacent organs. This slowly growing painless neoplasm was described by Steeper and Rosa some two and half decades ago in 1983. ${ }^{1}$ It can be mistaken both clinically and on microscopy for several other conditions and it is only the histopathological examination strengthened with immunohistochemical staining that conclusively proves the final diagnosis. Thus early detection of aggressive angiomyxoma requires a high index of suspicion, meticulous examination and thorough evaluation of all cases.

\section{CASE REPORT}

Mrs XY, 40 years old P3L3 presented to the gynaecological OPD with chief complaint of something coming out per vaginum for the last four to five months. The mass was increasing in size making squatting and walking difficult. She gave history of discharge per vaginum on and off for the last sixteen years. There is no history of abnormal bleeding per vaginum, local trauma, intake of hormones, urinary retention, constipation or bleeding per rectum. On examination, vitals stable, weight $45 \mathrm{~kg}$, mild pallor, abdomen soft. On local examination, there was an elongated mass $7-8 \mathrm{~cm}$ long prolapsing from the introitus similar to genital prolapse. On careful examination it was established that it was actually arising from the anterior vaginal wall. Vaginal mucosa covered it in upper two thirds like a tight sleeve, however, in the lower one third vaginal mucosal covering 
was absent and it appeared like a lobulated mass, pink in colour and firm to rubbery in consistency.

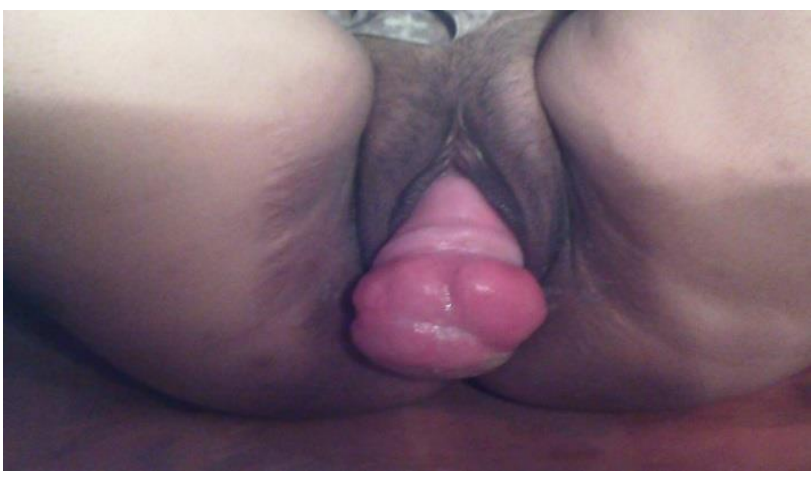

Figure 1: Clinical photograph: mass protruding through introitus about $8 \mathrm{~cm}$ long.

Urethral opening could be identified in the upper part on top of the mass close to the pubic symphysis. There were no areas of necrosis or haemorrhage and it did not bleed on touch. The upper limit of the mass seemed to be close to pubic symphysis. The cervix was identified to be lying in the normal position posterior to the mass. Inguinal lymph nodes were not palpable and rest of gynaecological examination was normal.

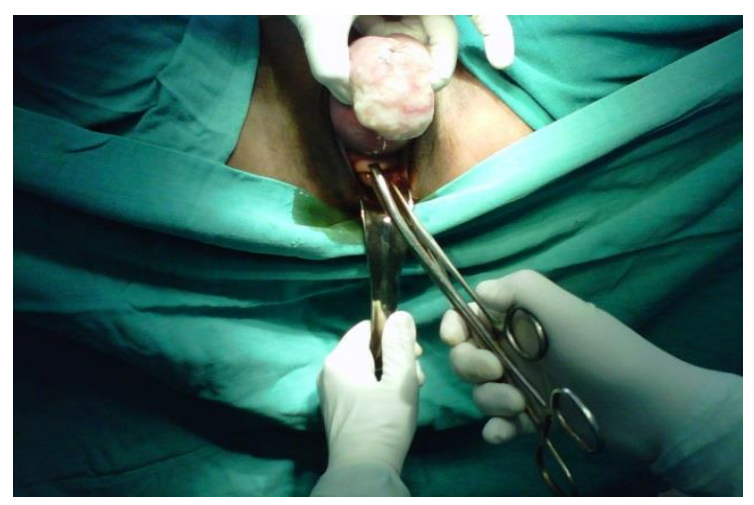

Figure 2: Clinical photograph: relationship of the mass with the cervix.

Her blood and urine investigations and chest X-ray were normal. Ultrasonography report showed it to be a lobulated hypo echoic mass seen indistinct from the anterior vaginal wall protruding outside the introitus. The lesion had distinct fat planes with the urethra and rectum. The uterus and cervix were normal and there was no pelvic lymphadenopathy. On CT scan it appeared as minimally enhancing SOL arising from the vaginal vault. A diagnostic wedge biopsy was performed and the report was that of a spindle cell tumour.

The patient was taken up for excision of the tumour. Informed consent was taken and the patient was explained that laparotomy would be done if need arises keeping in mind the possibility of deeper extension of the tumour into the pelvis.

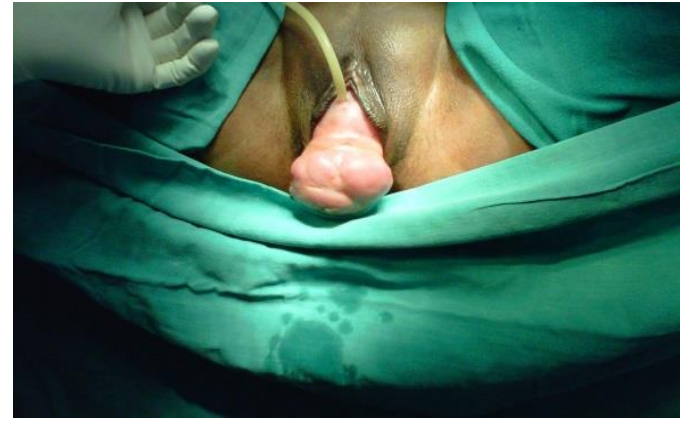

Figure 3: Clinical photograph: urethral opening on top of upper part of the mass.

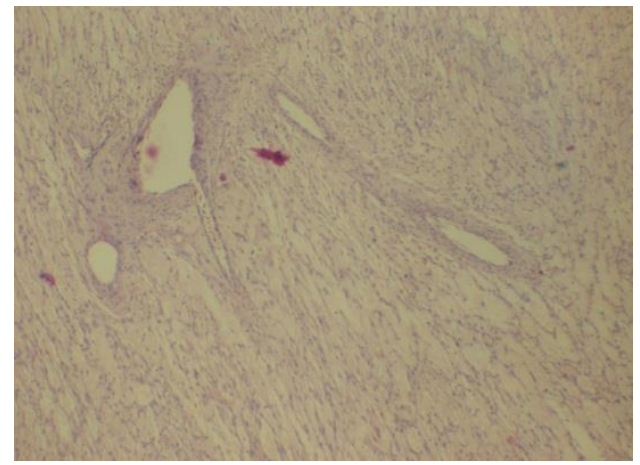

Figure 4: Photomicrograph of lesion: prominent blood vessels having thick walls in a myxoid background.

Incision was given at the junction of tumour mass and the vaginal mucosa after catheterisation of bladder. Tumour was dissected free from the overlying mucosa all around till base was reached. Great care was taken to avoid urethral injury as the urethra was in close proximity to the tumour. The whole tumour was excised in toto with wide surgical margin. On gross examination the tumour was soft, fleshy with no areas of haemorrhage or necrosis. Histopathology of the tumour was reported as aggressive angiomyxoma. Post-operative period was uneventful .A 15 month follow up has shown no recurrence of the tumour.

\section{DISCUSSION}

Aggressive angimyxoma is an uncommon distinctive myofibroblastic tumour of the pelvis and genital soft tissue. It mostly occurs in women of reproductive age group (female to male ratio is 6.6:1). The age distribution is wide with a peak incidence at 31-35 years, suggesting that estrogen may stimulate its growth. ${ }^{2}$ The process probably arises as a neoplastic proliferation of hormonally responsive mesenchymal cells. Hormone dependency is reinforced by the fact that tumours occurring during pregnancy have a rapid growth as there is a state of increased estrogen and progesterone production during this period. ${ }^{3}$ To our knowledge; fewer than 250 cases of these rare tumours have been reported in world literature. Tumours measure between $3 \mathrm{~cm}$ and $60 \mathrm{~cm}$ in greatest dimension. ${ }^{4}$ This neoplasm may be 
clinically misdiagnosed as vaginal polyps, vulvar lipoma, Bartholin's cyst, Gartner's duct cyst, vaginal cyst, vaginal prolapse and levator hernia. Differential diagnoses on inspection of the cut surface include myxoma, myxoid neurofibroma, myxofibrosarcoma, myxoid liposarcoma and myxoid leiomyosarcoma. Thus, the final diagnosis of aggressive angiomyxoma is always confirmed by histology.

In our case, the history and clinical presentation was similar to genital prolapse. However, careful examination and further investigations revealed the true nature of the tumour. It also demonstrates that, when vaginal wall descent is comparatively large, compared to the descent of cervix, other differential diagnoses should always be considered. ${ }^{5}$ Aggressive angimyxoma is a rare disease and there have been no large scale clinical trials to provide evidence based guidelines for the treatment of the disease. Complete surgical excision (wide excision with tumour free margins) is the main treatment modality. The recurrence rate varies from $36-70 \%$. Most of the recurrences are within the first three years and there is no correlation between size of the tumour and potential for recurrence. ${ }^{6}$ The extent of resection is limited due to close proximity of the tumour to genitourinary and anorectal structures. Treatment with GnRH agonists in estrogen and progesterone receptors positive tumors obviates repeat surgery for recurrence. ${ }^{7}$ Radiotherapy also reduces such recurrences.

Aggressive angiomyxoma is a locally aggressive tumor. However, recently cases of fatal metastatic aggressive angiomyxoma have been reported. ${ }^{8}$

Funding: No funding sources

Conflict of interest: None declared

Ethical approval: Not required

\section{REFERENCES}

1. Steeper TA, Rosai J. Aggressive angiomyxoma of the female pelvis and perineum: report of nine cases of a distinctive type of gynaecologic soft tissue neoplasm. Am J Surg Pathol. 1983;7:463-75.

2. Ribaldone R, Piantanida P, Surico D, Boldorini R, Colombo N, Surico N. Aggressive angiomyxoma of the vulva. Gynecol Oncol. 2004;95:724-8.

3. Htwe M, Deppish LM, Saint-Julien JS. Hormonedependent aggressive angiomyxoma of the vulva. Obstet Gynecol. 1995;86:697-9.

4. Mittal S, Kumar S, Baurasi P, Sharma MC. Aggressive angiomyxoma of the vulva-case report. Eur J Obstet Gynecol. 1998;81:111-3.

5. Chauhan MB, Malhotra V, Dahiya P, Nanda S. Aggressive angiomyxoma of the vagina masquerading as genital prolapse. J of Gynecol Surg. 2010;26(4):277-79.

6. Chan IM, Hon E, Ngai SW, and Ng TY, Wong LC. Aggressive angiomyxoma in females: is radical resection the only option? Acta Obstet Gynecol Scand. 2000;79(3):216-20.

7. Shinora N, Nonomura K, Ishikawa S, Seki H, Koyanagi T. Medical management of recurrent angiomyxoma with gonadotrophine releasing hormone agonist. Int J Urol. 2004;11:432-5.

8. Blandamura S, Cruz J, Faure Vergara L, Machado Puerto I, Ninfo V. Aggressive angiomyxoma :a second case of metastasis with patient's death. Human Pathol. 2003;34:1072-4.

Cite this article as: Dahiya M, Singhal C, Bansal S, Jinadal U. Aggressive angiomyxoma of vagina mimicking genital prolapse: a case report and review of literature. Int J Reprod Contracept Obstet Gynecol 2015;4:1231-3. 